Meulenkamp, T.M., Cardol, M., Hoek, L.S. van der, Francke, A.L., Rijken, M. Participation of people with physical disabilities: three-year trend and potential for improvement. Archives of

\begin{tabular}{|l|l|}
$\begin{array}{l}\text { Postprint } \\
\text { Version }\end{array}$ & 1.0 \\
\hline Journal website & http://www.archives-pmr.org/article/S0003-9993(13)00004-X/abstract \\
\hline Pubmed link & $\underline{\text { http://www.ncbi.nlm.nih.gov/pubmed/23313778 }}$ \\
\hline DOI & $10.1016 /$ j.apmr.2012.12.017
\end{tabular}

This is a NIVEL certified Post Print, more info at http://www.nivel.eu

\title{
Participation of People With Physical Disabilities: Three-Year Trend and Potential for Improvement
}

\author{
TineKe M. MEulenKamp, MSC ${ }^{\mathrm{A}}$, MieKe CARDOl, PhD ${ }^{\mathrm{A}}$, LuCAS S. VAN DER HOEK ${ }^{\mathrm{A}}$, \\ ANNEKe L. FrancKe, PHD, RN ${ }^{A, B}$, MieKE RIJKEN, PHD ${ }^{A}$ \\ ${ }^{a}$ NIVEL - Netherlands Institute for Health Services Research, Amsterdam, The Netherlands \\ ${ }^{\mathrm{b}}$ Department of Occupational and Public Health, EMGO+/VU University, Amsterdam, The \\ Netherlands
}

\section{Abstract}

Objective: To provide an insight into developments in participation over the period 2008 to 2010 among Dutch people with physical disabilities and into their demands for additional participation.

Design: Trend study with additional cross-sectional survey.

Setting: Community-dwelling people with physical disabilities.

Participants: A sample of 1868 (2008), 1900 (2009), and 2163 (2010) people

( $\geq 15 y$ ) with mild, moderate, or severe physical disability.

Interventions: Not applicable.

Main Outcome Measures: Eight indicators of participation within International Classification of Functioning, Disability and Health domains: use of neighborhood facilities, going out of the house, having paid work, performing volunteer services, visiting leisure facilities, performing club activities, meeting friends, and use of public transport.

Results: No increase in participation rates was found over the years 2008 to 2010. In 2010, 18\% of the people who did not have a paid job wanted to work, especially younger $(<40 \mathrm{y})$ people and more highly educated people, $30 \%$ wanted to do more activities in their leisure time, and $23 \%$ wanted more social contacts. People who did not participate in a specific activity in 2010 were more likely to have a desire for additional participation than were people who already participated. People with severe disability were less likely to want work; however, they did express a wish to increase their social activities.

Conclusions: Although no increase in participation was found, this does not imply that participation rates among people with physical disabilities have already reached optimal levels. Respondents' stated wish for additional participation provides potential for improvement. Further research should focus 
Meulenkamp, T.M., Cardol, M., Hoek, L.S. van der, Francke, A.L., Rijken, M. Participation of people with physical disabilities: three-year trend and potential for improvement. Archives of Physical Medicine and Rehabilitation: 2013, 94(5), 944-950

on individual values, participation appraisal, and interaction between individual and environmental characteristics to enhance participation.

Participation has been defined by the International Classification of Functioning, Disability and Health (ICF) as an individual's involvement in life situations. ${ }^{1}$ Participation is considered right for every individual, and therefore also for people with physical disabilities. ${ }^{2}$ However, people with physical disabilities still participate less than people without disabilities, for instance, in the domains of work and social activities. $^{3,4}$ and 5 They experience not only difficulties in their participation, such as inaccessible buildings and public transport, but also social impediments such as stereotyped images. ${ }^{\text {6, 7, 8, } 9 \text { and } 10}$

Initiatives are taken worldwide to enhance the participation of people with physical disabilities and to emphasize the necessity of equal opportunities to participate in a broad spectrum of life domains. ${ }^{2}$ and 11 In the Netherlands, the government has legislated for equal treatment of people with a disability or chronic illness in the areas of labor markets, education (2003), and housing (2009). ${ }^{12}$ In 2007, the Social Support Act was implemented, with the aim of improving the societal and social participation of all citizens. ${ }^{13}$ This act obliges municipalities to provide support to people with disabilities to help them become self-reliant. However, the Social Support Act does not define an optimum level of participation in terms of targets to be achieved.

We conducted a trend study to monitor participation rates over the period 2008 to 2010, immediately following the implementation of the Social Support Act, to obtain information on developments in the participation of people with physical disabilities. We also investigated whether people with disabilities had a desire for additional participation, to get an impression of what an optimum level of participation might be.

In this study, participation is operationalized as the ability to perform daytime activities through interaction with others in (a) the area outside domestic life, (b) interpersonal life, (c) major life activities, and (d) community, civic, and social life. These domains concur with the ICF domains for participation, 1 and they include the primary domains of participation as identified by rehabilitation stakeholders and researchers.14 and 15 The 2 research questions of our study were as follows: (1) what are the participation rates in various life domains among people with physical disabilities in the Netherlands, how have they developed over the years 2008 to 2010, and are there differences between subgroups and (2) do people with physical disabilities have a desire for additional participation and are there any differences in desire for additional participation between people who already participate and those who do not?

\section{METHODS}

\section{Sample}

Data used in this study were collected by questionnaires sent in the fall of 2008, 2009, and 2010 to a sample of 2242, 2180, and 2674 people, respectively, with physical disabilities in the Netherlands. The sample for this study was taken from the National Panel of people with Chronic illness or Disability (NPCD), a nationwide 
Meulenkamp, T.M., Cardol, M., Hoek, L.S. van der, Francke, A.L., Rijken, M. Participation of people with physical disabilities: three-year trend and potential for improvement. Archives of Physical Medicine and Rehabilitation: 2013, 94(5), 944-950

prospective panel study in the Netherlands.16 NPCD consists of approximately 4000 people with a medically diagnosed chronic somatic disease and/or physical disabilities. Members of NPCD are recruited in 2 ways: (1) on the basis of a diagnosis of a chronic disease from a random sample of practices of general practitioners in the Netherlands and (2) on the basis of a self-reported moderate or severe physical disability from several national population surveys conducted by the Netherlands Institute for Social Research, the Dutch Ministry of Housing, Spatial Planning and the Environment, and Statistics Netherlands. Members stay in the panel for a maximum of 4 years; in 2009 and 2010, a fairly large part of the panel was changed. For the purpose of this study, we selected panel members with a selfreported mild, moderate, or severe level of physical disability (see Measures); panel members without physical disabilities were excluded. Because a "mild" disability was not a sufficient condition to be included in NPCD, people with mild disability took part in the panel only if they had a medically diagnosed chronic disease. Other inclusion criteria were age $\geq 15$ years, not institutionalized, not terminally ill, and sufficient mastery of the Dutch language.

\section{Ethics}

The NPCD is registered with the Dutch Data Protection Authority; all data were collected and handled in accordance with the privacy protection guidelines of the authority, including informed consent.

\section{MEASURES}

\section{Participation}

Eight aspects of participation were measured; these were derived from the domains of the ICF1 and are shown in appendix 1. These aspects all had to have relevance for policymakers. At the start of the study, no short measurement instrument was available that covered all the domains of participation. Therefore, the questionnaire used in this study was partially based on self-developed items and partially based on items from existing Dutch questionnaires on paid and voluntary work and social contacts.17 and 18 We dichotomized the answer options for each item to obtain an indicator as to whether a respondent participated (to some extent) in a specific domain (see appendix 1). The indicators chosen for participation and the content validity and the comprehensibility of the draft questionnaire were critically appraised in a steering committee with experts and stakeholders: representatives of patient organizations, the Ministry of Health, Welfare and Sports, the Ministry of Social Affairs and Employment, and the Dutch Council of the Chronically ill and the Disabled (an umbrella organization). The steering committee was positive about the draft questionnaire, but it stressed the necessity of including an item about public transport, as this was considered an important precondition for participation. This advice was followed.

\section{Desire for additional participation}

The 2010 survey also included questions about the desire for additional participation, presented in appendix 1. 
Meulenkamp, T.M., Cardol, M., Hoek, L.S. van der, Francke, A.L., Rijken, M. Participation of people with physical disabilities: three-year trend and potential for improvement. Archives of Physical Medicine and Rehabilitation: 2013, 94(5), 944-950

\section{Background characteristics}

The following sociodemographic characteristics were included: age, sex, education, and household type. Furthermore, the level of disability was determined by a selfreported, validated Dutch questionnaire that comprises 24 items and deals with activities in daily life and the ability to see/hear.19 The level of physical disability was first defined by the level of motor disability. People with mild motor disabilities were those who had problems with 1 or more activities in daily life, mostly concerning household tasks, such as doing heavy housework or minor repairs. Moderate motor disability is defined as having problems with various activities, not only in household tasks but also in mobility. Severe motor disability is defined as being unable to perform at least 1 activity independently, that is, needing support. People with severe disability also report problems with self-care activities. Second, people with mild motor disabilities who also had moderate/severe seeing or hearing problems were classified as having "moderate" or "severe" physical disability. NPCD panelists with severe disability are relatively older, with lower levels of education, and more likely to be living alone compared with people with milder disabilities.

\section{STATISTICAL ANALYSIS}

To answer research question 1 , a logistic regression model was used in which each of the participation indicators was regressed on year, age, sex, severity of physical disability, education, and household type. The model had a parameter for each year and parameters for the interaction of each of the other independent variables with variable year. There was no constant in the model. The parameterization was such that the parameters for each year were estimates of the average in a standard population. Clustered sandwich estimators were used for standard errors because of the dependencies resulting from measuring part of the people in more than 1 year. After model estimation, linear combinations of the parameters were formed to test for significance in linear trends. The participation rates were computed for a standardized population to avoid the problem of changes in participation rates due to differences in the sample composition for each year (see table 1). The characteristics of this standardized population were derived from data of earlier national samples of people with motor disabilities (distributions of sex, age, and severity of disability), and of people with moderate to severe physical disabilities (education level and household type) because no data were available on these latter background characteristics for people with mild physical disability.20 To explore turnover in participation from year to year, crosstabs were made. Differences in the direction of turnover based on background characteristics were analyzed using chi-square tests. To answer research question 2, we computed percentages of people reporting a desire for additional participation. Differences between subgroups were tested using chisquare tests. The $\mathrm{P}$ values lower than .01 were considered significant. The statistical program Stata 11a was used for the analyses. 
Meulenkamp, T.M., Cardol, M., Hoek, L.S. van der, Francke, A.L., Rijken, M. Participation of people with physical disabilities: three-year trend and potential for improvement. Archives of Physical Medicine and Rehabilitation: 2013, 94(5), 944-950

\section{[TABLE 1]}

\section{RESULTS}

\section{Sample characteristics}

Table 1 shows the sociodemographic characteristics and the distribution of the severity of disability within the sample in 2008, 2009, and 2010. The overall response to our questionnaire was $83 \%, 87 \%$, and $81 \%$, respectively. Nonresponse analyses showed no differences in response rate for subgroups defined by sample characteristics except for the 15 to 39 years age category, in which response rates were lower $(\mathrm{P}<.05)$.

\section{Participation rates}

Table 2 displays information on the participation rates of the entire group of people with physical disabilities in the years 2008 to 2010. In all 3 years, 20\% of the people did volunteer work and about 35\% (of those younger than 65y) had paid work for at least 12 hours a week. About 45\% used public transport, and around $40 \%$ made regular use of 2 or more neighborhood facilities. Around $30 \%$ of the people visited leisure and entertainment facilities on a monthly basis, and 30\% took part in club activities on a weekly basis, while about $45 \%$ met friends weekly.

\section{[TABLE 2]}

Additional analyses showed differences in participation rates between subgroups in all 3 years. More women used public transport and took part in club activities than men. Fewer people aged $\geq 65$ years went out of the house every day than people aged 40 to 64 years; more young people $(<40 \mathrm{y})$ had a paid job. Fewer people with low levels of education had a paid job, did volunteer work, or visited leisure and entertainment facilities than people with medium or high levels of education. Furthermore, more highly educated people visited leisure and entertainment facilities than people with medium levels of education. People living alone made use of public transport more often and were more likely to visit friends weekly. Finally, the greater the degree of disability, the less likely people were to go out of the house every day or have a paid job. People with severe disability made use of public transport and visited leisure and entertainment facilities less often.

\section{Trends from 2008 to 2010}

No increase or decrease was found in participation rates over the 2008 to 2010 period (see table 2). However, at the subgroup level, a decrease in participation was found for the indicator going out of the house every day for people with medium levels of education $(\mathrm{P}=.003)$ and for using public transport for the age group 40 to 64 years $(\mathrm{P}=.006)$ and people with medium levels of education $(\mathrm{P}<.001)$. The turnover in our sample from nonparticipation to participation on each of the indicators from year to year (2008/2009 and 2009/2010) was around 10\% (range, $5 \%-13 \%)$; only for paid $(<65 y)$ and volunteer work, a turnover of about $1 \%$ and 
Meulenkamp, T.M., Cardol, M., Hoek, L.S. van der, Francke, A.L., Rijken, M. Participation of people with physical disabilities: three-year trend and potential for improvement. Archives of Physical Medicine and Rehabilitation: 2013, 94(5), 944-950

about 3\%, respectively, was found. The turnover from participation to nonparticipation was slightly above $10 \%$ (range, $8 \%-16 \%$ ); for paid work and volunteer work, a turnover of $2 \%$ and $5 \%$ was found. There were no differences in the direction of turnover based on background characteristics.

\section{Desire for additional participation in 2010}

Table 3 describes the percentage of people who reported a desire for additional participation. People without a paid job or volunteer work were asked whether they wanted to do this; $18 \%$ of them expressed the desire to get a paid job, while $6 \%$ wanted to do volunteer work. Furthermore, about 30\% of the total group expressed the desire to become more active in their leisure time, and 23\% would welcome more social contacts (would like to meet more often with existing friends and/or new friends). The desire for additional participation was related to age; more young people than old people wanted to have a paid job, to do more activities in their leisure time, and to have more social contact. People with severe disability compared with people with mild or moderate disability wanted to go out more frequently, to do more activities in their leisure time, and to have more social contact. However, no differences were found in the need to have a paid job or to do volunteer work. More highly educated people were likely to want to have a paid job, do volunteer work, or have more social contact than people with lower levels of education. Furthermore, people living alone wanted to go out more often, do more activities in leisure time, and have more social contact.

\section{[TABLE 3]}

\section{Desire for additional participation in relation to participation level}

Table 4 shows the differences in the desire for additional participation between people who already participated and people who did not participate. A substantial proportion of both groups had participation demands. However, more people who did not participate had a desire for additional participation than people who already participated.

\section{[TABLE 4]}

\section{Discussion}

This study shows that the participation of people with physical disabilities in the Netherlands in various domains of life has not increased over the period 2008 to 2010, despite national policy and local efforts to facilitate the participation of people with physical disabilities. However, in 2010, people expressed a desire for additional participation, particularly people who were not participating already.

Previous studies found differences in participation between people with physical disabilities and those without, for instance, in the domains of work and social life., 4 and 5 Our results seem to confirm this difference; participation in paid and volunteer work (36\% and $20 \%$, respectively) was low compared with what was found in another study for the general population ${ }^{21}$ (67\% and 39\%). Participation rates in 
Meulenkamp, T.M., Cardol, M., Hoek, L.S. van der, Francke, A.L., Rijken, M. Participation of people with physical disabilities: three-year trend and potential for improvement. Archives of Physical Medicine and Rehabilitation: 2013, 94(5), 944-950

various domains vary according to sex, age, education, type of household, and severity of disability. In answer to our first research question, we found no increase in participation rates over the years 2008, 2009, and 2010. We found a small decrease in participation rates in 2 domains for people with medium levels of education and for the age group 40 to 64 years. Although our study is not an evaluation of the Social Support Act, it seems that initiatives taken by the government to support equal opportunities and to increase opportunities for participation have not (yet) had an effect on increasing participation, at least not at the population level. In another study, evaluation of the Social Support Act suggests that though local governments have increased their efforts aimed at enabling participation, they have had difficulties reaching specific groups such as people experiencing trouble in making social contacts. ${ }^{22}$ We can also question whether an increase is feasible in the light of societal developments due to the economic recession. Although it is important to evaluate the exact contribution of the environment in increasing participation, this is very complicated because of the complex interplay of personal and environmental characteristics. ${ }^{23,24 \text { and } 25}$ However, in answer to our second research question, our results show that a substantial percentage of the people with physical disabilities have a desire for additional participation, suggesting a potential for improvements in participation. This demand comes both from people who already participate in a certain domain but who want to participate more and even more so from people who do not already participate in a certain domain. From other studies, we know that part of the people with disabilities perceive their participation as poor. ${ }^{7 \text { and } 8}$ Different people led different lives in different contexts. As a consequence, participation preferences and demands will also vary, as shown in our study. For example, young people ( $<40 \mathrm{y}$ ) and people with a high level of education more often expressed a desire to work than older people $(\geq 40 \mathrm{y})$ and people with a low level of education. Also, people with severe physical disability more often expressed a desire for additional social activities than for work activities. Participation preferences seem to be related to not only different phases in life, education, or level of disability but also personal endeavor or opportunities. Thus, when support is needed, it must be tailor-made and fit the specific personal needs, as is also advocated by client-centered rehabilitation approaches. ${ }^{26}$ We think such individual-centered approaches could benefit from more research into personal values, an appraisal of different types of participation and of the comparative assessments people make with regard to participation, to highlight ways in which participation by people with disabilities can be optimized. A followup study using the panel could focus on changes in participation at the individual level and possible determinants, for example, the occurrence of life events. Such a study could also contribute to our understanding of the aspects that determine a turnover in participation.

\section{Study limitations}

The 8 indicators for participation in this study do not cover all aspects of participation, although they do cover important domains of life, as defined in the ICF.1 Although we carefully considered choices in defining the indicators for participation, we are aware that they may not do justice to the differences in interpretation of what participation involves by different individuals. Besides, 
Meulenkamp, T.M., Cardol, M., Hoek, L.S. van der, Francke, A.L., Rijken, M. Participation of people with physical disabilities: three-year trend and potential for improvement. Archives of Physical Medicine and Rehabilitation: 2013, 94(5), 944-950

although a clear contrast is being made by dichotomizing the data, a possible change within the 2 categories is not visible. Another potential limitation concerns our study sample because it is not necessarily representative of the population of people with physical disabilities. We corrected for underrepresentation of certain groups, for example, of younger people $(<40 \mathrm{y})$, by using a standard population. We could not correct for the fact that in our study we probably had overrepresentation of people with mild physical disability in combination with a chronic illness. Despite the limitations, a strength of our study is the repeated measurement of participation in a nationwide sample, which gives an insight into trends in participation.

\section{CONCLUSIONS}

To conclude, though no increase in participation rates was found in various domains over the period 2008, 2009, and 2010, there seems potential for improvement as a substantial group expressed a desire to participate more.

\section{SUPPLIER}

a. Stata, version 11.0; StataCorp, 4905 Lakeway Dr, College Station, TX 77845.

\section{[APPENDIX 1]}

\section{REFERENCES}

1 World Health Organization International Classification of Functioning, Disability and Health World Health Organization, Geneva (2001)

2 United Nations Convention on the rights of persons with disabilities and optional protocol United Nations, New York (2006)

3 M.M. van Santvoort Disability in Europe: policy, social participation and subjective wellbeing [dissertation] University of Groningen, Groningen (2009)

$4 \mathrm{C}$. van Campen, M. Cardol When work and satisfaction with life do not go hand in hand: health barriers and personal resources in the participation of people with chronic physical disabilities Soc Sci Med, 69 (2009), pp. 56-60

5 D. Pope, C. Bambra Has the Disability Discrimination Act closed the employment gap? Disabil Rehabil, 27 (2005), pp. 1261-1266

6 M. Fallahpour, K. Tham, M.T. Joghataei, H. Jonsson Perceived participation and autonomy: aspects of functioning and contextual factors predicting participation after stroke J Rehabil Med, 43 (2011), pp. 388-397

7 M.L. Larsson Lund, J. Lexell Perceived participation in life situations in persons with late effects of polio J Rehabil Med, 40 (2008), pp. 659-664

8 M. Larsson Lund, A. Nordlund, L. Nygård, J. Lexell, B. Bernspång Perceptions of participation and predictors of perceived problems with participation in persons with spinal cord injury J Rehabil Med, 37 (2005), pp. 3-8

$9 \mathrm{~J}$. Wee, R. Lysaght Factors affecting measures of activities and participation in persons with mobility impairment Disabil Rehabil, 31 (2009), pp. 1633-1642

10 D. Goodley Disability studies: an interdisciplinary introduction Sage, London (2011)

11 World Health Organization and World Bank Group World report on disability

World Health Organization, Geneva (2011) 
Meulenkamp, T.M., Cardol, M., Hoek, L.S. van der, Francke, A.L., Rijken, M. Participation of people with physical disabilities: three-year trend and potential for improvement. Archives of Physical Medicine and Rehabilitation: 2013, 94(5), 944-950

12 Dutch government. Wet gelijke behandeling op grond van handicap of chronische ziekte. (Law equal treatment on grounds of disability or chronic illness). Available at: http://wetten.overheid.nl/BWBR0014915. Accessed June 29, 2012.

13 M. Kroneman, M. Cardol, R. Friele (De)centralization of social support in six Western European countries Health Policy, 106 (2012), pp. 76-87

14 S. Magasi, J. Hammel, A. Heinemann, G. Whiteneck, J. Bogner Participation: a comparative analysis of multiple rehabilitation stakeholders' perspectives J Rehabil Med, 41 (2009), pp. 936-944

15 G. Whiteneck, M.P. Dijkers Difficult to measure constructs: conceptual and methodological issues concerning participation and environmental factors Arch Phys Med Rehabil, 90 (2009), pp. S22-S35

16 M. Rijken, M. van Kerkhof, J. Dekker, F.G. Schellevis Comorbidity of chronic disease: effects of disease pairs on physical and mental functioning Qual Life Res, 14 (2005), pp. 45-55

17 The Netherlands Institute for Social Research. Permanent onderzoek naar de leefsituatie (POLS). (Continued research on living conditions). Available at:

http://www.scp.nl/Onderzoek/Bronnen/Beknopte_onderzoeksbeschrijvingen/Permanent_on derzoek_naar_de_leefsituatie_POLS. Accessed June 29, 2012.

18

The Netherlands Institute for Social Research. Aanvullend voorzieningengebruikonderzoek (AVO). (Research on the use of supplementary facilities). Available at:

http://www.scp.nl/Onderzoek/Bronnen/Beknopte_onderzoeksbeschrijvingen/Aanvullend_vo orzieningengebruikonderzoek_AVO. Accessed June 29, 2012.

19 M. de Klerk, J. ledema, C. van Campen SCP-maat voor lichamelijke beperkingen op basis van AVO 2003 [Measure of physical disability on the basis of AVO 2003] The Netherlands Institute for Social Research, The Hague (2006)

20 M. de Klerk (Ed.), Meedoen met beperkingen: Rapportage gehandicapten 2007. (Joining in with limitations: reporting disability 2007), The Netherlands Institute for Social Research, The Hague (2007)

$21 \mathrm{~T}$. Meulenkamp, L. van der Hoek, M. Cardol Deelname aan de samenleving van mensen met een beperking en ouderen: Rapportage participatiemonitor 2011. [Social participation of people with disabilities and the elderly: reporting participation monitor 2011] Utrecht: NIVEL (2011)

22 M. de Klerk, R. Gilsing, J. Timmermans (Eds.), Op weg met de Wmo. Evaluatie van de Wet maatschappelijke ondersteuning 2007-2009 [Evaluation of the Social Support Act 2007-2009], The Netherlands Institute for Social Research, The Hague (2010)

23 L. Noreau, K. Boschen Intersection of participation and environmental factors: a complex interactive process Arch Phys Med Rehabil, 91 (2010), pp. S44-S53

24 T. Mallinson, J. Hammel Measurement of participation: intersecting person, task, and environment Arch Phys Med Rehabil, 91 (2010), pp. S29-S33

25 R. Escorpizo, S. Graf, A. Marti et al. Domain sets and measurement instruments on participation and environmental factors in spinal cord injury research Am J Phys Med Rehabil, 90 (2011), pp. S66-S78

26 M. Law, S. Baptiste, J. MillsClient-centred practice: what does it mean and does it make a difference? Can J Occup Ther, 62 (1995), pp. 250-257 
Meulenkamp, T.M., Cardol, M., Hoek, L.S. van der, Francke, A.L., Rijken, M. Participation of people with physical disabilities: three-year trend and potential for improvement . Archives of Physical Medicine and Rehabilitation: 2013, 94(5), 944-950

\section{TABLES}

Table 1 Sample characteristics per measuring year (2008, 2009, 2010) and characteristics of the defined standard population (percentages)

\begin{tabular}{|c|c|c|c|c|}
\hline Characteristic & $\begin{array}{l}2008 \\
(n=1868)\end{array}$ & $\begin{array}{l}2009^{*} \\
(n=1900)\end{array}$ & $\begin{array}{l}2010^{*} \\
(n=2163)\end{array}$ & $\begin{array}{l}\text { Standard } \\
\text { Population }\end{array}$ \\
\hline \multicolumn{5}{|l|}{ Sex } \\
\hline Male & 34.5 & 36.3 & 35.0 & 35 \\
\hline Female & 65.5 & 63.7 & 65.0 & 65 \\
\hline \multicolumn{5}{|l|}{ Age $(y)$} \\
\hline $15-39$ & 3.9 & 4.3 & 6.1 & 15 \\
\hline $40-64$ & 44.3 & 42.8 & 40.9 & 45 \\
\hline 65 and older & 51.9 & 52.8 & 53.0 & 40 \\
\hline \multicolumn{5}{|l|}{ Education level $^{\dagger}$} \\
\hline Low & 45.4 & 42.6 & 40.5 & 50 \\
\hline Medium & 40.0 & 39.8 & 41.5 & 35 \\
\hline High & 14.6 & 17.6 & 18.0 & 15 \\
\hline \multicolumn{5}{|l|}{ Household type } \\
\hline Living alone & 34.5 & 34.6 & 38.0 & 25 \\
\hline $\begin{array}{l}\text { Living with } \\
\text { partner } \\
\text { and/or other } \\
\text { persons }\end{array}$ & 65.5 & 65.4 & 62.0 & 75 \\
\hline \multicolumn{5}{|l|}{ Disability severity } \\
\hline Mild & 30.4 & 30.2 & 20.3 & 55 \\
\hline Moderate & 48.7 & 46.5 & 52.6 & 30 \\
\hline Severe & 20.9 & 23.3 & 27.1 & 15 \\
\hline
\end{tabular}

* Members stay in the panel for a maximum of 4 years. In our sample, 1405 cases were added in 2009 and 957 cases in 2010; these cases include few panel members who did not respond to a last years' questionnaire.

$\dagger$ Low, no education, primary school or vocational training; medium, secondary or vocational education; high, professional higher education or university. 
Meulenkamp, T.M., Cardol, M., Hoek, L.S. van der, Francke, A.L., Rijken, M. Participation of people with physical disabilities: three-year trend and potential for improvement . Archives of Physical Medicine and Rehabilitation: 2013, 94(5), 944-950

Table 2 Participation (\%) of people with physical disabilities (95\% confidence interval)

\begin{tabular}{|c|c|c|c|c|}
\hline Indicator for Participation & 2008 & 2009 & 2010 & $P$ (change over time) \\
\hline Regular use of 2 or more neighborhood facilities* & $44.3(40.8-47.8)$ & $39.5(36.5-42.6)$ & $38.5(35.6-41.5)$ & NT \\
\hline Going out of the house daily & $85.4(82.6-87.8)$ & $82.3(79.6-84.8)$ & $81.3(78.3-83.9)$ & .030 \\
\hline Use of public transport & $47.9(44.8-50.9)$ & $47.0(43.9-50.0)$ & $44.2(41.2-47.3)$ & .084 \\
\hline Being employed $(\geq 12 \mathrm{~h} \text { per week })^{\dagger}$ & $35.8(31.2-40.6)$ & $34.3(30.0-38.7)$ & $35.9(31.8-40.3)$ & .953 \\
\hline Doing volunteer work & $20.4(18.0-22.9)$ & $20.0(17.6-22.5)$ & $20.0(17.6-22.6)$ & .825 \\
\hline Visiting entertainment/leisure facilities monthly & $28.5(25.8-31.3)$ & $32.0(29.1-35.0)$ & $27.9(25.2-30.8)$ & .777 \\
\hline Performing club activities weekly & $33.8(30.9-36.7)$ & $31.8(29.0-34.8)$ & $31.6(28.8-34.6)$ & .278 \\
\hline Meeting friends weekly & $43.6(40.7-46.6)$ & $46.5(43.4-49.6)$ & $43.8(40.8-46.9)$ & .934 \\
\hline
\end{tabular}

Abbreviation: NT, not tested.

* The indicator "use of public neighborhood facilities" was not included in the survey in 2008; we used available data from the panel measurement in fall 2007 instead. Trend analysis was not performed because of a small change in response category.

$\dagger<65 \mathrm{y}$ of age, a minimum of $12 \mathrm{~h}$ a week is the definition used in the Netherlands for the economically active population.

Table 3 Demand for additional participation* among respondents in relation to background characteristics in 2010 (percentages)

\begin{tabular}{|c|c|c|c|c|c|c|c|c|c|c|c|c|c|c|c|}
\hline \multirow[b]{2}{*}{ Would Like to... } & \multirow{2}{*}{$\begin{array}{l}\text { Total } \\
\text { Group }\end{array}$} & \multirow[b]{2}{*}{$n$} & \multicolumn{3}{|c|}{ Age $(y)$} & \multicolumn{2}{|c|}{ Sex } & \multicolumn{3}{|c|}{ Disability Severity } & \multicolumn{3}{|c|}{ Education Level } & \multicolumn{2}{|c|}{ Household Type } \\
\hline & & & $15-39$ & $40-64$ & $\geq 65$ & Male & Female & Mild & Moderate & Severe & Low & Medium & High & Alone & With Others \\
\hline $\begin{array}{l}\text { Make use of certain } \\
\text { neighborhood } \\
\text { facilities (more often) }\end{array}$ & 12.7 & 2056 & 9.2 & 11.5 & 14.2 & 13.2 & 12.5 & $5.7^{\dagger}$ & $12.0^{\dagger}$ & $19.7^{\dagger}$ & 13.4 & 12.4 & 11.4 & 15.0 & 11.3 \\
\hline $\begin{array}{l}\text { Go somewhere more } \\
\text { often }\end{array}$ & 37.8 & 2063 & 34.1 & 37.0 & 38.9 & 35.4 & 39.1 & $13.6^{\dagger}$ & $39.6^{\dagger}$ & $52.8^{\dagger}$ & 36.4 & 38.2 & 38.1 & $46.1^{\dagger}$ & $32.6^{\dagger}$ \\
\hline Have a paid job $(<65 y)^{\ddagger}$ & 17.9 & 573 & $38.0^{\dagger}$ & $15.9^{\dagger}$ & NA & 15.8 & 18.8 & 19.8 & 19.3 & 14.4 & $11.8^{\dagger}$ & $19.1^{\dagger}$ & $28.1^{\dagger}$ & 15.6 & 19.1 \\
\hline Do volunteer work & 5.9 & 1380 & $14.6^{\dagger}$ & $9.8^{\dagger}$ & $2.0^{\dagger}$ & 5.6 & 6.2 & 6.5 & 5.7 & 6.2 & $3.5^{\dagger}$ & $6.4^{\dagger}$ & $11.0^{\dagger}$ & 6.0 & 6.0 \\
\hline $\begin{array}{l}\text { Do more activities in } \\
\text { leisure time }\end{array}$ & 29.8 & 1980 & $41.0^{\dagger}$ & $33.9^{\dagger}$ & $25.1^{\dagger}$ & $25.7^{\dagger}$ & $32.1^{\dagger}$ & $14.5^{\dagger}$ & $29.6^{\dagger}$ & $42.4^{\dagger}$ & 26.6 & 30.5 & 34.0 & $35.0^{\dagger}$ & $26.6^{\dagger}$ \\
\hline Have more social contact & 23.3 & 2075 & $34.6^{\dagger}$ & $24.7^{\dagger}$ & $20.9^{\dagger}$ & 20.6 & 24.8 & $13.4^{\dagger}$ & $25.3^{\dagger}$ & $27.8^{\dagger}$ & $19.3^{\dagger}$ & $25.4^{\dagger}$ & $26.3^{\dagger}$ & $30.3^{\dagger}$ & $19.1^{\dagger}$ \\
\hline
\end{tabular}

Abbreviation: NA, not applicable.

* No data are available for public transport.

$\dagger$ Significant relation between need and background characteristic $\left(\chi^{2}\right.$ test, $\left.P<.01\right)$.

$¥$ Asked to people who did not have a paid job or did not do volunteer work in 2010 .

Table 4 Difference between participating and nonparticipating respondents in demand for additional participation in 2010 (percentages)

\begin{tabular}{|c|c|c|c|c|c|}
\hline Indicator & Would Like to... & $\begin{array}{l}\text { Subgroup I: No Participation } \\
\text { as Defined by Indicator }\end{array}$ & $\begin{array}{l}\text { Subgroup II: Participation } \\
\text { as Defined by Indicator }\end{array}$ & $P$ & $\mathrm{n}$ \\
\hline $\begin{array}{l}\text { Regular use of } 2 \text { or more } \\
\text { neighborhood facilities }\end{array}$ & $\begin{array}{l}\text { Make use of certain } \\
\text { neighborhood facilities } \\
\text { (more often) }\end{array}$ & 16.8 & 5.7 & $<.0001$ & 2056 \\
\hline Going out of the house daily & Go somewhere more often & 52.0 & 32.0 & $<.0001$ & 2034 \\
\hline $\begin{array}{l}\text { Visiting leisure/entertainment } \\
\text { facilities monthly }\end{array}$ & $\begin{array}{l}\text { Do more activities in } \\
\text { leisure time }\end{array}$ & 32.9 & 22.5 & $<.0001$ & 1943 \\
\hline Meeting friends weekly & Have more social contact & 32.0 & 11.6 & $<.0001$ & 2015 \\
\hline
\end{tabular}


Appendix 1 Chosen indicators for participation: questions and response formats

\begin{tabular}{|c|c|c|}
\hline Indicator for Participation & Question and Response Format* & Demand for Additional Participation \\
\hline $\begin{array}{l}\text { Making use of } 2 \text { or more } \\
\text { neighborhood facilities } \\
\text { regularly }\end{array}$ & $\begin{array}{l}\text { How often do you make use of the } \\
\text { following neighborhood facilities: } \\
\text { (a) supermarket/other shops, (b) library, } \\
\text { (c) community center, (d) public garden/ } \\
\text { green space? For each of the facilities: } \\
\text { Regularly/sometimes/almost never/not } \\
\text { available in the immediate vicinity }\end{array}$ & $\begin{array}{l}\text { Do you make use of the neighborhood } \\
\text { facilities that you want to make } \\
\text { use of? (yes/no, I want to make } \\
\text { use of ... more often) }\end{array}$ \\
\hline Getting out of the house daily & $\begin{array}{l}\text { How often do you get out of the house? } \\
\text { Daily/weekly/monthly/less than once per month }\end{array}$ & $\begin{array}{l}\text { Would you like to go somewhere } \\
\text { more often? (yes/no) }\end{array}$ \\
\hline $\begin{array}{l}\text { Occasional or regular use of } \\
\text { public transport }\end{array}$ & $\begin{array}{l}\text { Do you ever make use of public transport, eg, bus, } \\
\text { tram, metro, train, or regional taxi (public transport } \\
\text { from door to door)? No/occasionally/regularly }\end{array}$ & ND \\
\hline $\begin{array}{l}\text { Having paid work for at least } \\
12 \mathrm{~h} \text { per week as employee } \\
\text { and/or self-employed } \\
\text { businessperson }\end{array}$ & $\begin{array}{l}\text { Do you have paid work at the moment as an employee } \\
\text { or self-employed businessperson? No/yes for ... hours } \\
\text { per week as an employee/yes for ... hours per week } \\
\text { as a self-employed businessperson }\end{array}$ & $\begin{array}{l}\text { Would you like to do paid work? } \\
\text { (yes/no/don't know) (only for } \\
\text { people who did not have } \\
\text { paid work) }\end{array}$ \\
\hline Performing volunteer services & $\begin{array}{l}\text { Do you perform volunteer services? Defined as unpaid } \\
\text { work in an organized setting (eg, for a sports club, } \\
\text { church, school, political party). Yes/no }\end{array}$ & $\begin{array}{l}\text { Would you like to do volunteer services } \\
\text { (yes/no/don't know) (only for } \\
\text { people who did not already) }\end{array}$ \\
\hline $\begin{array}{l}\text { Visiting } 1 \text { or more leisure or } \\
\text { entertainment facilities } \\
\text { once a month or more }\end{array}$ & $\begin{array}{l}\text { How often do you visit } 1 \text { or more of the following places: } \\
\text { (a) café, restaurant, (b) amusement park or museum, } \\
\text { (c) cinema or theater? At least once a week/at least } \\
\text { once a month/less than once per month/rarely or never }\end{array}$ & $\begin{array}{l}\text { Can you do the activities you want } \\
\text { to do in your leisure time? (yes/no, } \\
\text { would like to do more activities } \\
\text { alone/no, would like to do more }\end{array}$ \\
\hline $\begin{array}{l}\text { Performing } 1 \text { or more club } \\
\text { activities at least once a week }\end{array}$ & $\begin{array}{l}\text { How often do you participate in the following club activities: } \\
\text { (a) sports in a club, (b) dance/music/drama/hobby club? } \\
\text { At least once a week/at least once a month/less than } \\
\text { once per month/rarely or never }\end{array}$ & $\begin{array}{l}\text { activities with people in an organized } \\
\text { way/no, would like to do more } \\
\text { activities with people in } \\
\text { a nonorganized way/no, would } \\
\text { like to do more activities with } \\
\text { other people who have a physical } \\
\text { disability) }\end{array}$ \\
\hline $\begin{array}{l}\text { Meeting friends or good } \\
\text { acquaintances at least } \\
\text { once a week }\end{array}$ & $\begin{array}{l}\text { How often do you meet friends or good acquaintances? } \\
\text { These are limited to meetings with people who do not } \\
\text { live in your house and with whom you have at least } \\
\text { a short conversation (not just a greeting). At least } \\
\text { once a week/twice a month/once a month/less than } \\
\text { once per month/rarely or never/not applicable }\end{array}$ & $\begin{array}{l}\text { Do you have enough contact and } \\
\text { meetings with other people? } \\
\text { (yes/no, would like to meet } \\
\text { the people I know more often/no, } \\
\text { would like to meet new people/no, } \\
\text { would like to meet more people with } \\
\text { a physical disability/no, would like } \\
\text { to meet more people without } \\
\text { a physical disability) }\end{array}$ \\
\hline
\end{tabular}

Abbreviation: ND, no data.

* Words in bold give the answer categories for the cutoff used for the participation indicator. "Not applicable" was coded "0" (nonparticipation). 